\title{
O TOQUE NA VISÃO DO FISIOTERAPEUTA HOSPITALAR
}

\author{
Michelle F.M. Jamarim ${ }^{1}$ \\ Claudinei J. G. Campos \\ Camila Z. da Silva ${ }^{3}$ \\ Cibele L. Siqueira ${ }^{4}$ \\ Samira M. S. Monteiro \\ ${ }^{1}$ Fisioterapeuta - Doutoranda em Ciências da Saúde pela FEnf-UNICAMP \\ ${ }^{2}$ Enfermeiro - Prof. Doutor, orientador da FEnf - UNICAMP \\ ${ }^{3}$ Fisioterapeuta - Mestre em Ciências da Saúde pela FEnf - UNICAMP \\ ${ }^{4}$ Enfermeira - Doutora em Ciências da Saúde pela FEnf - UNICAMP \\ ${ }^{5}$ Fisioterapeuta - Mestranda em Ciências da Saúde pela FEnf - UNICAMP
}

INTRODUÇÃO: Apenas 7\% dos nossos pensamentos são expressos por palavras enquanto $93 \%$ acontecem por mensagens inconscientes não verbais. Entre os meios de linguagem corporal, o toque é o sentido mais aguçado por fazer interagir, revelar sentimentos e intenções. Tocar transmite afeto, segurança, proteção e permite ao paciente sentir-se valorizado e único ou pode ser ruim, se não for permitido ou dependendo da forma que é tocado. O toque é essencial no trabalho do fisioterapeuta, por incorporar uma relação muito íntima com o corpo, capaz de influenciar na qualidade da assistência. OBJETIVO: compreender os significados atribuídos ao toque por fisioterapeutas que atuam em ambiente hospitalar. MÉTODO: Trata-se de um estudo de caso qualitativo. A população constituiu-se de 18 fisioterapeutas atuantes em um hospital ao sul de Minas Gerais. A amostra foi composta de modo intencional e fechada por exaustão. O critério de inclusão foi no mínimo 6 meses de contratação. Para coleta de dados foi utilizado um roteiro para entrevista semiestruturada elaborado a partir do modelo proposto por Turato. As entrevistas ocorreram de dezembro de 2015 a março de 2016, gravadas em áudio e transcritas pela pesquisadora. Para a análise dos dados utilizou-se a análise temática de conteúdo. O estudo foi aprovado pelo Comitê de Ética e Pesquisa da Faculdade de Ciências Médicas da Universidade Estadual de Campinas (UNICAMP) sob o parecer número: 1136177. Todas as normas da Resolução 466/12, que normatiza pesquisas com seres humanos foram cumpridas. RESULTADOS: emergiram duas categorias: Sentimentos do fisioterapeuta relacionados ao toque e a Dificuldade em falar sobre o toque expressivo traduz deficiência na formação. Conclusão: para os fisioterapeutas entrevistados o toque significa 
seu instrumento principal de trabalho e o toque expressivo parece não ser conhecido pelo fisioterapeuta por provável deficiencia na formação acadêmica. Sugere-se uma intervenção educativa com esses profissionais de maneira a conscientizá-los da importância do toque expressivo e fazê-los incorporar novos valores ao toque, proporcionando uma assistência individualizada que contemple as necessidades do paciente, uma melhor relação e comunicação fisioterapeuta / paciente e uma assistência mais humanizada.

Descritores: fisioterapeuta; toque terapêutico; comunicação não verbal. Linha de pesquisa: Processo de Cuidar em Saúde e Enfermagem no Adulto e Idoso. 